\title{
Research Results on Influence of Hydraulic Hammer Design Parameters
}

\author{
Irina Teterina ${ }^{1}{ }^{*}$, Igor Ugrumov $^{1}$, Ivan Teterin ${ }^{1}$, and Andrey Korneev ${ }^{2}$ \\ ${ }^{1}$ Siberian State Automobile and Highway University (SibADI), 644080, Omsk, Mira Ave, 5, Russia \\ ${ }^{2}$ Rubtsovsk Industrial Institute (branch) Polzunov Altai State Technical University, 658207, \\ Rubtsovsk, 2/6, Tractornaya st., Russia
}

\begin{abstract}
The article presents the results of the theoretical research on the influence of the design parameters on the output characterictics of a hydraulic hammer. The hydraulic hammer under the study has a hydraulic percussive mechanism of a permanent pressure-type structure with a spool free control unit. A design model of a hydraulic percussive mechanism with a spool free control unit has been developed. The mathematical model of the hydraulic percussive mechanism of a permanent pressure-type structure with a spool free control unit is presented. The oscillogram resulting from the theoretical studies, which defines the operation of the hydraulic percussive mechanism, is presented. A range of the rational zones for selecting the main design parameters of the hydraulic percussive mechnism is obtained.
\end{abstract}

\section{Introduction}

The climatic conditions of the Russian Federation are an important factor in determining the prospects for the development of mechanisms for the destruction of frozen soils [1].

The worldwide practice shows the development of a significant number of hydraulic percussive mechanisms with an impact energy of 200-30,000 J and frequency between 4 and $100 \mathrm{~Hz}$.

The area of application of hydraulic percussive mechanisms for various operations is wide [2]. In recent decades, there have been significant changes in the structure of a construction work, including the work with hydraulic hammers [2].

Owing to the high wear and tear on public utilities equipment, there has been a sharp increase in the number of emergency and repair works related to the destruction of frozen soils during the repair of heating, hot and cold water systems during the winter period [3].

\section{Main part}

Understanding that the hydraulic hammer modernization reserves are almost exhausted, there is a need to develop a new generation of hydraulic percussive mechanisms that allow efficient operations related to the destruction of frozen soils [4].

\footnotetext{
*Corresponding author: iateterina@mail.ru
} 
The most common designs have become hydraulic percussive mechanisms with spool and valve distributors $[1,5]$. Such constructions have their own advantages, which include compactness and equilibrium from static forces of liquid pressure, as well as the ease of control, and the disadvantages which have complexity and labour intensity of precision pairs production, a limited speed and low maintenance [6].

The design analysis has showed that the hydraulic mechanisms of a permanent pressuretype structure are the most promising, provided that a rational operating mode is implemented that maintains the working and idling forces at the highest possible constant level [7].

The arguments above have led to the conclusion that a method for controlling a distributor with elastic shells and the development of hydraulic percussive mechanisms with a spool free control unit on its basis are necessary to be created. [8].

In order to determine the effects of the main parameters of the hydraulic hammer on its output, in order to select the rational zones of the main structural parameters, a design model of a hydraulic percussive mechanism with a spool free control unit has been developed. The calculation scheme takes into account the parameters of a pumping unit and soil, the parameters of an actuator and control unit. [9].

The main functional elements of the diagram (Fig. 1) are the operating and reversing chambers, a body, a hammer, a spool free control unit with two annular locking and regulating elements, a drain and pressure hydraulic lines with the hydropneumatic batteries.

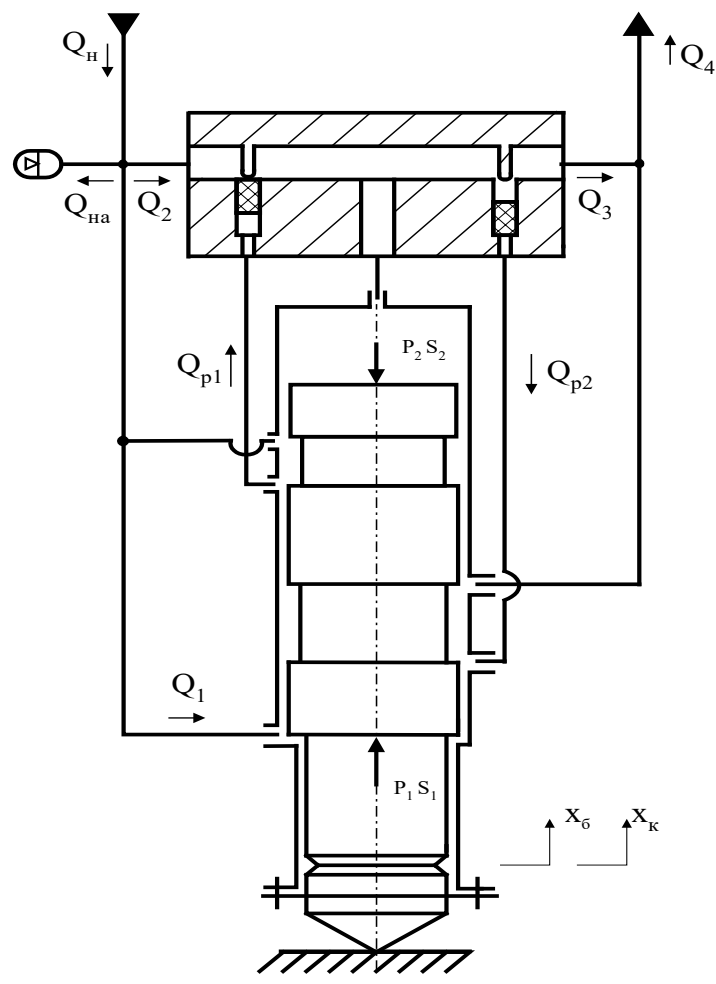

Fig. 1. The calculation scheme of a hydraulic percussive mechanism of a a permanent pressuretype structure with a spool free control unit.

The next stage of a structural modelling is the development of a mathematical model of the hydraulic percussive mechanism of a permanent pressure-type structure with a spool free control unit on the basis of a pre-determined calculation scheme. 
The mathematical model of operation of a hydraulic percussive mechanism of a permanent pressure-type structure with a spool free control unit comprises equations of a piston-block movement, a body, the equations of the working fluid flow in the operating chambers and hydraulic lines, forming coefficients and logical operators.

The movement of the hammer and shell between the impacts is represented with the differential impacts of the following type [7].

$$
\left\{\begin{array}{c}
\mathrm{m}_{\mathrm{b}} \ddot{\mathrm{x}}_{\mathrm{b}}=\mathrm{P}_{1} \mathrm{~S}_{1}-\mathrm{P}_{2} \mathrm{~S}_{2}-\mathrm{F}_{\mathrm{tr}} \operatorname{sign} \dot{\mathrm{x}}_{\mathrm{bk}}-\mathrm{F}_{\mathrm{B}}-\mathrm{m}_{\mathrm{b}} \cdot \mathrm{g} \cdot \cos \alpha \\
\mathrm{m}_{\mathrm{k}} \ddot{\mathrm{x}}_{\mathrm{k}}=\mathrm{P}_{2} \mathrm{~S}_{2}-\mathrm{P}_{1} \mathrm{~S}_{1}+\mathrm{F}_{\mathrm{tr}} \operatorname{sign} \dot{\mathrm{x}}_{\mathrm{bk}}+\mathrm{F}_{\mathrm{B}}-\mathrm{F}_{\mathrm{p}}-\mathrm{m}_{\mathrm{k}} \cdot \mathrm{g} \cdot \cos \alpha
\end{array}\right.
$$

where $m_{b} \ddot{x}_{b}$ is the acceleration and mass of the hammer; $m_{k} \ddot{x}_{k}$ is the acceleration and mass of the shell; $\mathrm{P}_{1}, \mathrm{P}_{2}$ are the pressure in operating and idling chambers; $\mathrm{S}_{1}, \mathrm{~S}_{2}$ are the area of the piston from the side of the idling and operating chambers; $F_{t r}$ is a frictional force of seals; $F_{B}$ is a fluid friction force; $F_{p}$ is a feed force; $\alpha$ is an angle of deviation of the axis of the percussive mechanism from the vertical; sign $\dot{\mathrm{x}}_{\mathrm{bk}}$ is a function that defines a sign with a variable.

The speed of movement of the hammer relative to the body is determined as follows:

$$
\dot{\mathrm{x}}_{\mathrm{bk}}=\mathrm{V}_{\mathrm{bk}}=\dot{\mathrm{x}}_{\mathrm{b}}-\dot{\mathrm{x}}_{\mathrm{k}},
$$

where $\dot{\mathrm{x}}_{\mathrm{b}}, \dot{\mathrm{x}}_{\mathrm{k}}$ are the absolute movement speeds of the hammer and body.

A change pressure speed $\left(\dot{\mathrm{P}}_{\mathrm{H}}\right)$ of the pressure hydraulic line is determined with the formula $[7,10]$ :

$$
\dot{\mathrm{P}}_{\mathrm{H}}=\frac{1}{\left(\frac{\mathrm{v}_{\mathrm{TH}}}{\mathrm{E}_{\mathrm{P}}}+\frac{\mathrm{V}_{01} \mathrm{P}_{01}}{\mathrm{P}_{\mathrm{H}}^{2}}\right)} \cdot\left(\mathrm{Q}_{\mathrm{H}}-\mathrm{Q}_{1}\right),
$$

where $\mathrm{V}_{\mathrm{TH}}$ is volume of liquid in the pressure hydraulic line; $\mathrm{E}_{\mathrm{P}}$ is a reduced module of volumetric elasticity of the hydraulic system; $V_{01}, P_{01}$ are an initial charge volume and initial charge pressure of the hydropneumatic battery; $Q_{H}$ is a pump output flow; $Q_{1}$ is a liquid flow rate in the idling chamber; is a pump output pressure.

Working fluid pressure in the idling chamber [11]

$$
\mathrm{P}_{1}=\mathrm{P}_{\mathrm{H}}-\lambda_{\mathrm{TH}} \frac{8 \rho \mathrm{l}_{\mathrm{TH}}}{\pi^{2} \mathrm{~d}_{\mathrm{T}}^{5}} \cdot\left|\frac{\mathrm{Q}_{\mathrm{H}}+\mathrm{Q}_{1}}{2}\right| \cdot\left(\frac{\mathrm{Q}_{\mathrm{H}}+\mathrm{Q}_{1}}{2}\right),
$$

where $\lambda_{\mathrm{TH}}$ is a pressure loss factor along the length; $d_{T}, \mathrm{l}_{\mathrm{TH}}$ is a inner diameter and length of the pressure hydraulic line to the idling chamber; $\rho$ is a fluid density.

For the operating chamber, the pressure rate is $[7,11]$ :

$$
\dot{\mathrm{P}}_{2}=\frac{\mathrm{E}_{\mathrm{P}}}{\mathrm{V}_{\mathrm{op}}+\left(\mathrm{L}_{\mathrm{b}}-\mathrm{x}_{\mathrm{bk}}\right) \cdot \mathrm{S}_{2}}\left(\mathrm{Q}_{3}-\mathrm{Q}_{4}\right) \text {, }
$$

where $V_{o p}$ is an initial volume of operating chamber; $L_{b}$ is a maximum hammer stroke; $x_{b k}$ is a movement of the hammer relative to the body.

The flow rate of $\left(Q_{3}\right)$ liquid from the operating stroke chamber depends on $S_{2}$ working area and the initial speed $\dot{\mathrm{x}}_{\mathrm{sbk}}$ of movement of the hammer and is determined as follows [12]:

$$
\mathrm{Q}_{3}=\mathrm{S}_{2} \cdot \dot{\mathrm{x}}_{\mathrm{sbk}}
$$

where $\dot{\mathrm{x}}_{\mathrm{sbk}}=\mathrm{R} \cdot \dot{\mathrm{x}}_{\mathrm{bk}}$ is an initial speed of the hammer after the impact with the tool; $R$ is a rate of recovery of the hammer speed at the impact; $\dot{\mathrm{x}}_{\mathrm{sbk}}$ is a hammer speed before the impact.

$Q_{4}$ liquid flow rate at the outlet of the drainage line is determined with the calculated dependence $[7,12]$ : 


$$
\mathrm{Q}_{4}=\mu \frac{\pi \mathrm{d}_{\mathrm{sl}}^{2}}{4} \cdot \sqrt{\frac{2}{\rho}}\left(\mathrm{P}_{2}-\mathrm{P}_{\mathrm{atm}}\right),
$$

where $\mu$ is a flow rate; $d_{s l}$ is a diameter of a drain line; $P_{2}$ is an operating stroke chamber pressure; $P_{\text {atm }}$ is an air pressure.

The final condition of the phase of the windup is the position of the hammer relative to the body of the percussive mechanism, in which the distributor connects the controlled operating stroke chamber to the pressure hydraulic line, i.e.

$$
\mathrm{x}_{\mathrm{bk}} \leq \mathrm{l}_{\mathrm{v}},
$$

where $l_{v}$ is a stroke of the moving parts in the phase of the windup (calculated coordinate of switching forces).

The equations characterizing the parameters of the hydraulic system in the braking $\left(\mathrm{L}_{\mathrm{b}}-\mathrm{l}_{\mathrm{v}} \leq \mathrm{x}_{\mathrm{bk}} \leq \mathrm{L}_{\mathrm{b}}\right)$ and operating phases $\left(\mathrm{L}_{\mathrm{b}} \leq \mathrm{x}_{\mathrm{bk}} \leq-\mathrm{L}_{\mathrm{b}}\right.$, ) are as follows [13]:

- for the idling chamber, $P_{1}$ pressure is determined with (3) and (4) formulas, taking into account the direction of movement of the hammer. $Q_{1}$ liquid flow rate in the idling chamber is determined with the formula $[7,14]$ :

$$
\mathrm{Q}_{1}=\left\{\begin{array}{c}
\mathrm{S}_{1} \cdot \dot{\mathrm{x}}_{\mathrm{bk}} \text { at } \mathrm{L}_{\mathrm{b}}-\mathrm{l}_{\mathrm{v}} \leq \mathrm{x}_{\mathrm{bk}} \leq \mathrm{L}_{\mathrm{b}} \\
-\mathrm{S}_{1} \cdot \dot{\mathrm{x}}_{\mathrm{bk}} \text { at } \mathrm{L}_{\mathrm{b}} \leq \mathrm{x}_{\mathrm{bk}} \leq-\mathrm{L}_{\mathrm{b}}
\end{array}\right.
$$

- the fluid pressure in the operating chamber is $[3,7]$ :

$$
\mathrm{P}_{2}=\mathrm{P}_{\mathrm{H}}-\lambda_{\mathrm{TH}} \frac{8 \rho \mathrm{l}_{\mathrm{TR}}}{\pi^{2} \mathrm{~d}_{\mathrm{T}}^{5}} \cdot\left|\frac{\mathrm{Q}_{\mathrm{H}}+\mathrm{Q}_{2}}{2}\right| \cdot\left(\frac{\mathrm{Q}_{\mathrm{H}}+\mathrm{Q}_{2}}{2}\right),
$$

where $Q_{2}$ is a fluid flow from the pressure hydraulic line into the operating chamber;

- $Q_{2}$ liquid flow rate in the operating stroke chamber during braking and working stroke, taking into account the direction of movement of the hammer, is based on the calculated dependence[7,11]:

$$
\mathrm{Q}_{2}=\left\{\begin{array}{c}
\mathrm{S}_{2} \cdot \mathrm{x}_{\mathrm{bk}} \text { at } \mathrm{L}_{\mathrm{b}}-\mathrm{l}_{\mathrm{v}} \leq \mathrm{x}_{\mathrm{bk}} \leq \mathrm{L}_{\mathrm{b}} \\
-\mathrm{S}_{1} \cdot \dot{\mathrm{x}}_{\mathrm{bk}} \text { at } \mathrm{L}_{\mathrm{b}} \leq \mathrm{x}_{\mathrm{bk}} \leq-\mathrm{L}_{\mathrm{b}}
\end{array}\right.
$$

- liquid flow rate to control a closing control element due to conductivity of the hydraulic line is determined [1]:

$$
\mathrm{Q}_{\mathrm{p} 1}=\mathrm{Q}_{\mathrm{p} 2}=\mu \frac{\pi \mathrm{d}_{\mathrm{y}}^{2}}{4} \cdot \sqrt{\frac{2}{\rho} \Delta \mathrm{P}},
$$

where $d_{\mathrm{y}}$ is a diameter of a hydraulic line to control a closing control element; $\Delta \mathrm{P}$ is a pressure difference on a closing control element.

The mathematical model of a hydraulic percussive mechanism of a permanent pressure type with a spool free control unit is a system of differential and algebraic equations with variable coefficients [13]. The mathematical model was solved using numerical methods implemented in the MATLAB environment.

In the study of the operating processes of the hydraulic percussive mechanism of the permanent pressure structure with a spool free control unit, it has been found that the following basic design parameters have a significant influence on the output: $S_{2}$ area of the hammer on the side of the operating stroke chamber; $m_{b}$ mass of the hammer; $\mathrm{x}_{\mathrm{bk}}$ the displacement of the hammer; $P_{01}$ pressure of the initial charge; $Q_{H}$ flow of the pump and $V_{01}$ initial volume of the gas cavity of the hydropneumatic battery.

The range of variable parameters was determined based on the technical characteristics of the 2 size group excavator $[1,10]$. In the theoretical studies, the main parameters varied as follows: 
- the area of the hammer on the working stroke chamber side $\left(S_{2}\right)$ is within 10.3810-4 and 18.5910-4 $\mathrm{m}^{2}$;

- the diameter of the hammar shank on the working stroke chamber side $\left(d_{2}\right)$ is within 0.066 and $0.071 \mathrm{~m}$;

- mass of the hammer $\left(m_{6}\right)$ is within 20 and $50 \mathrm{~kg}$;

- the stroke of the hammer $\left(x_{b k}\right)$ is within 0.05 and $0.17 \mathrm{~m}$;

- the initial charge pressure of the network hydropneumatic battery $\left(P_{01}\right)$ is within 2 and $8 \mathrm{MPa}$;

- the initial volume of the network hydropneumatic battery $\left(V_{01}\right)$ is within $0.0002 \ldots 0.001 \mathrm{~m}^{3}$;

- the pump flow $\left(Q_{H}\right)$ is within $0.7510^{-3}$ to $210^{-3} \mathrm{~m}^{3} / \mathrm{s}$ (or from $45 \ldots 120$ litre per minute).

At the same time, a number of constant parameters were accepted. These included:

- the area of the hammer on the idling stroke chamber side $\left(S_{l}\right)$ is equal to $3.7910-2 \mathrm{~m}^{2}$;

- the diameter of the hammer shank on the side of the chamber $\left(d_{l}\right)$ is equal to $0.079 \mathrm{~m}$;

- the diameter of the hammer piston $(D)$ is $0.082 \mathrm{~m}$.

As an example, Figure 2 shows the oscillogram obtained as a result of the theoretical studies, which shows the operation of the hydraulic percussive mechanism, which characterizes the change in pressure in the chamber of $P_{2}$ operating and $P_{1}$ idling strokes (Fig. 2.a), the movement and speed of the hammer $V_{b k}$ (Fig. 2. b) in different phases of the percussive mechanism.

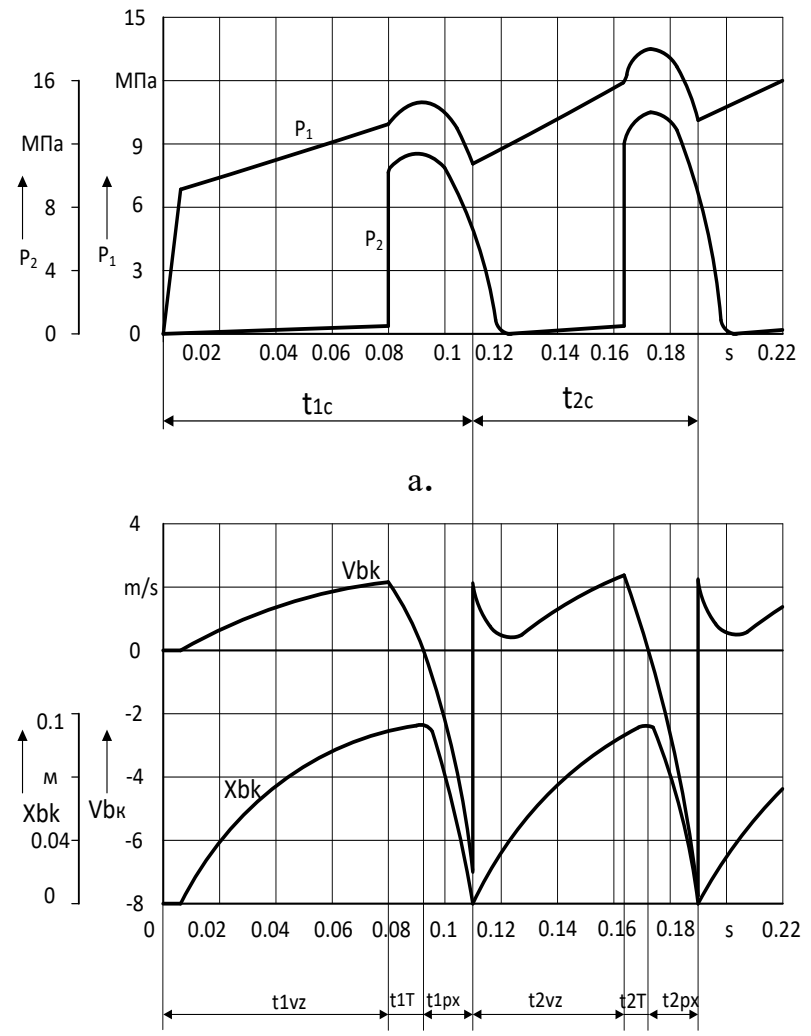

6.

Fig. 2. The results of the theoretical studies of the operating process of the hydraulic percussive of a permanent pressure-type structure with spool free control unit:

a) pressure in the chamber at operating and idling; b) movement and speed of the hammer. 
The operating cycle of the percussive mechanism is divided into two periods, the starting and the main, which on the oscillogram are defined by $t_{1 c}$ and $t_{2 c}$ time respectively $[5,7]$. The windup phase is characterized with $t_{1 v z}$ and $t_{2 v z}$ time; the braking phase is characterized with $t_{1 \mathrm{~T}}$ and $t_{2 \mathrm{~T}}$ time, and the operating phase is characterized with $t_{1 \mathrm{px}}$ and $\mathrm{t}_{2 \mathrm{px}}$ time. In this example, the following values of the design parameters are taken: $\mathrm{Q}_{\mathrm{H}}=$ $210^{-3} \mathrm{~m}^{3} / \mathrm{s} ; \mathrm{S}^{2}=15.5910^{-4} \mathrm{~m}^{2} ; \mathrm{x}_{\mathrm{b}}=0.087 \mathrm{~m} ; \mathrm{m}_{\mathrm{b}}=35 \mathrm{~kg} ; \mathrm{P}_{01}=7.0 \mathrm{MPa} ; \mathrm{V}_{01}=0.3510^{-3} \mathrm{~m}^{3}$.

\section{Conclusion}

The mathematical model developed has made possible to research the influence of the design parameters on the output characteristics of the hydraulic hammer and to obtain a range of the rational zones of choice of the main design parameters of the hydraulic percussive mechanism.

The rational values of the main design parameters of the hydraulic percussive mechanism are determined. The recommendations are given for the hydraulic hammers for the excavators of the 2 size group on the values of $S^{2}$ hammer area $\left(S_{2}=0.001038 \ldots\right.$ $0.001859 \mathrm{~m}^{2}$ ) when the hammer mass changes within 20 and $50 \mathrm{~kg}$.

The rational values of the design stroke of the hammer have been obtained in the considered range $x_{b k}=0.05 \ldots 0.17 \mathrm{~m}$ depending on its mass.

The results of the studies of the closing control element speed when selecting the parameters of the width and the stroke in the range of $h=0.001 \ldots 0.0015 \mathrm{~m}, \mathrm{~B}=0.004 \ldots 0.006$ $\mathrm{m}$ allows taking the response time of the closing and distributing element in an order of magnitude greater than the operating cycle time of the hydraulic percussive mechanisms.

Such a design parameter as the pump flow $\left(Q_{H}\right)$ is determined with the main operating parameter that shows the output characteristics of the hydraulic percussive mechanism.

In addition, the results obtained were used as a basis for determining the productivity and energy intensity parameters for the development of frozen soils by an excavator using hydraulic hammers.

\section{References}

1. N.S. Galdin, I.A. Semenova, V.N. Galdin, Analysis of the Striker Stroke Impact on the Hydropneumatic Impact Devices Energy Performance, Journal of Physics: Conference Series, vol. 1260(11), P. 112010 (2019)

2. A.B. Letopolsky, P.A. Korchagin, I.A. Teterina, Working equipment of the singlebucket excavator for the development of frozen ground, IOP Conference Series: Materials Science and Engineering, vol. 709(4), P. 044027 (2020)

3. V.E. Shcherba, V.S. Shcherbakov, N.S. Galdin, A.V. Grigor'ev, D.A. Trukhanova, Analysis of the Effect of the Ratio of Discharge Pressure to Suction Pressure on the Characteristics of a Piston Hybrid Power Machine with Gas Suction Capacity, Chemical and Petroleum Engineering, vol. 54(1-2), pp. 100-106 (2018)

4. Y. Kazantsev, G. Glazyrin, S. Shayuk, O. Tanfilyev, V. Fyodorova, Hydro unit active power controller minimizing water hammer effect, Proceedings of the 2020 Ural Smart Energy Conference, No. 9281252, pp. 47-50 (2020)

5. R. Rodríguez, M. Bascompta, Vibration analysis and empirical law definition for different equipment in a civil construction, Applied Sciences (Switzerland) vol. 10(14), P. 4689 (2020) 
6. A.O. Bondarenko, R.P. Naumenko, Comprehensive solution of recycling waste from stone processing industry, Naukovyi Visnyk Natsionalnoho Hirnychoho Universytetu, vol. 2019(4), pp. 96-101 (2019)

7. O.D. Alimov, S.A. Basov, Hydraulic vibration percussive systems (Moscow, Science, 1990)

8. K.G. Pugin, D.V. Vlasov, I.R. Gimadeev, Expansion of the technological capabilities of KOMATSU PC 220 excavator by installing a hydraulic hammer, Costruction and road machinery. No. 10, Pp. 6-10 (2020)

9. B. Romuald, Z. Jian, Y.X. Dong, D. Claire, Assessment and Performance Evaluation of Water Hammer in Hydroelectric Plants with Hydropneumatic Tank and Pressure Regulating Valve, Journal of Pressure Vessel Technology, Transactions of the ASME vol. 143(4), P. 041401 (2021)

10. P.A. Korchagin, I.A. Teterina, A.B. Letopolsky, Effect of tire dynamic characteristics on vibration load at the operator's workplace, Journal of Physics: Conference Series, vol. 1441(1), P. 012097 (2020)

11. A.B. Letopolsky, P.A. Korchagin, I.A. Teterina, Working equipment of the singlebucket excavator for the development of frozen ground, IOP Conference Series: Materials Science and Engineering, vol. 709(4), P. 044027 (2020)

12. K.B. Kyzyrov, A.A. Mitusov, O.S. Reshetnikova, Parametric study of the liquid distribution system of hydraulic hammer, University papers. vol. 3 (72), Pp. 37-40 (2018)

13. A.S. Trubin Research and selection of rational parameters of hydraulic hammer, Moscow Automobile and Road State Technical University (MADI) Journal. vol. 1 (52), Pp. 42-46 (2018)

14. A.A. Serov, A.N. Folchanov, A.M. Nakhaev, Application of hydraulic hammers in construction production, High technologies in construction complex. vol. 1, Pp 119122 (2020) 